\title{
ASPECTS REGARDING THE ENERGY SECURITY IN THE MIDDLE EAST
}

\author{
Ionuţ Alin CÎRDEI \\ "Nicolae Bălcescu" Land Forces Academy, Sibiu, Romania \\ cirdei_alin@yahoo.com
}

\begin{abstract}
Ensuring energy security is a concern for all the world's countries. For a long time, the issue of energy security has been looked at from the point of view of ensuring the energy resources necessary for the functioning of the economy and society and, implicitly, from the perspective of reducing dependence on imported energy resources. In reality, however, energy security must also be addressed from the perspective of states with energy resources, as their security can be jeopardized by disturbances that may occur during the operation or transport process or due to lower prices. Middle East countries, rich in energy resources, are currently vulnerable due to global oil price declines and instability and conflict in the region. This vulnerability may affect the supply of energyconsuming states and their energy security in the medium and long term, and not only.
\end{abstract}

KEYWORDS: energy security, resources, oil, crisis, Middle East

\section{Introduction}

In general terms, "energy security refers to the provision of energy resources necessary for the proper functioning of the economy of a state and for ensuring the well-being of citizens, in optimal quantities, at acceptable prices, in a continuous flow and with minimal impact on the environment, by adopting the necessary measures to secure supply sources, transport corridors and processing and storage capacities simultaneously with the conduct of a research and innovation activity in order to achieve long-term energy stability" (Cîrdei, 2015, p. 80). Dependence on energy resources is not proof of the fact that energy security is jeopardized. The fact that a country relies on energy imports, irrespective of its form and type, does not jeopardize its energy security "provided that the flow of energy resources keeps constantly from surplus areas (energy resource producers) to areas with deficit (consumers of energy resources)" (Fattouh, 2007, p. 9).

The evolution of international events has highlighted the need to extend the scope of this definition, as energy security refers not only to energy-consuming states but also to resource-holders. Affecting a state's energy security can occur due to events happening at any point in the supply chain at different times. The duration of the damage and its intensity depends on a multitude of factors. Events taking place in extraction areas, if they have a limited 
duration, have an acceptable impact on providing the necessary resources for the proper functioning of the entire system due to the existence of stocks and the length of the entire flow. Of the possible factors that may affect security of supply, the most important are, in our opinion, political military factors that can create instability for long periods of time. Prolonged political crises, internal tensions, as in the case of the Arab Spring and Colorful Revolutions in North Africa, internal or inter-state conflicts can cause large spatial and temporal crises. The Middle East region, due to its past tension, the present complex situation and the possible trends, is an area that needs to be given greater attention. The rich hydrocarbon resources make this area an area of great importance for the large consumers of fossil energy resources, but at the same time it is one of the major vulnerabilities to ensuring energy security. Knowing the specificity of this area, understanding the mechanisms that appear here can be a way to ensure energy security and, at the same time, provide signals at the right time to reorient and re-establish relationships of dependence. Increasing the energy efficiency and the share of renewable energy resources in some countries will be offset by increased energy needs in other emerging countries such as India and China as well as other North African, Asian and South American states. Consequently, the demand for fossil energy resources will remain constant and will even slightly increase globally, although the share of oil in the energy mix will likely fall.

The European Union will have the same concerns about reducing the consumption of energy resources and, in particular, fossil resources, but other developing countries will not pay too much attention to alternative energy sources, being concerned about economic development. Also, in some European countries and beyond, there is a tendency to eliminate nuclear energy, which can create an energy shortage that is most easily offset by increasing the consumption of fossil energy resources.

Under these circumstances, the Middle East will continue to be a major source of oil and an alternative to oil from Venezuela or Russia, which are not always trusted partners and have used in the past their energy resources as pressure tools in international relations.

\section{A brief Overview of the Middle}

\section{East Area}

The Middle East area is a quite large area occupying the Arabian Peninsula, but also some neighboring areas, with Saudi Arabia, United Arab Emirates, Bahrain, Iran, Iraq, Israel and Yemen as the main states to which we can add Egypt, Turkey, Georgia etc. In our analysis, we will focus on the states situated in the Arabian Peninsula.

This area is characterized by strong tensions between the constituent states and between the states in the region and other states due to political, economic, religious factors, etc. The origin of tensions between the states of the region is lost in the darkness of time, and can be identified at the time of the emergence of Islam, which gave rise in time to the shaping of two divergent religious trends: Sunni and Shiite. This religious tension was exacerbated when the great colonial powers allowed for the establishment of new states, whose borders were arbitrarily and geometrically drawn, without taking into account the ethnic and religious distribution of the population, giving birth to some States where there are powerful minorities, and in which the minority class has often taken power and exercised it to the detriment of the majority. In this context, the states in the region are trying to protect their own minorities in the territory of other states through direct or indirect involvement in domestic affairs, which gives rise to even more tensions and conflicts. These tensions 
are felt within states, but especially between states, for example, between Saudi Arabia, the most important Sunni state in the region and Iran, the most important Shiite state. Political and religious tensions are even greater as we have Middle Eastern countries where the leading class is Sunni and most of the population is Shiite or vice versa.

The Middle East region has seen numerous wars in recent decades, including: the Arab-Israeli wars, the war between Iran and Iraq, Kuwait's invasion by Iraq, the first Gulf War between the international coalition and Iraq, the Second Gulf War, the revolution in Egypt, the civil war in Syria, the perpetual conflict between Israel and the Palestinian territories, etc., plus the terrorist organizations fighting the state, the ISIS offensive in Iraq and Syria, the civil war in Yemen, etc. These conflicts have a strong impact on the whole region, but also affect the energy security of both the states in the region and energyconsuming states. Conflicts have a direct impact on the production and distribution of energy resources by affecting the ability of states to extract, process, transport energy resources, but also have an indirect impact on states' capacity to exploit resources and thus on energy security, by reducing the competitiveness of the states and their capacity to face the market challenges due to the lack of investment and the aging of the technology.

States in this area can be divided into at least three categories at the moment, from a stability and security perspective: on the one hand, we have the states that are governed by totalitarian regimes, capable of maintaining full control over the territory, institutions and processes of exploitation of resources, even at the risk of human rights violations, on the other hand we have unstable states, marked by internal conflicts such as Syria and Iraq, where the capacity of extracting energy resources is affected, as well as the international credibility. The third category could be represented by states such as Iran, which have a dominant position in the area, have strong institutions capable of controlling the entire territory and governing the state, but which are in a tense relationship with other states and have been subjected to drastic international sanctions, which can limit their role on the energy resource market, and which can be restored at any time.

The conflicting history of the area is also amplified by the rich resources the area has, and they attract as a magnet the great powers, pursuing their interests through the maintenance of conflicts and direct support of one party to the detriment of the other.

Energy security is not only about access to energy resources, but also about the existence of markets. For a long time, the issue of energy security has been analyzed only from the perspective of energy consumers, considering that the energy resource holders are in a privileged position. However, the evolution of recent years has highlighted the extremely high vulnerability of states with energy resources to developments in the international security environment. Over time, energy-consuming states have tried to find alternative solutions, reduce their dependence, and increase their energy efficiency, while energy-rich states have done little to keep up with international developments, and their economies, and implicitly national security, suffered from disruptions that took place in the energy and security field. We are thus able to analyze the situation of the states of the Middle East, states that have important hydrocarbon reserves but which are in a strong state of insecurity, with multiple tensions and divergent interests fed and sustained by the great powers that have chosen, as in the cold war period, to lead an indirect war, called proxy war.

Middle Eastern countries face a series of challenges to their own security, challenges that come from both the international environment and the evolution of the energy security issue. The main 
challenges that we have identified as of major importance for the near future are:

- Domestic and international terrorism, individual, state-owned or endorsed by terrorist organizations such as ISIS;

- Dictatorial regimes and attempts to combat them, for example the Syrian regime or the possible tensions that may arise in Saudi Arabia or other states in the;

- Internal conflicts, where armed groups are fighting against state authorities, most often supported by forces outside the country;

- External and inter-regional conflicts, such as the conflict in Yemen where Iran and Saudi Arabia are actually facing, the conflicts between Israel and Palestine;

- Decreasing and maintaining the oil price at a low level, due to the emergence of shale oil, the increase in production but also the attempt to impose unofficial sanctions on some states;

- Increased attention given to renewable energy by energy-intensive states, due to the issue of protecting the environment and ensuring energy security;

- Technological evolution, which allows more efficient exploitation, with less impact on the environment, but requires investment and research;

- Lack of investment in energy and aging of transport infrastructure, which has a limited life span and technical characteristics that are outdated by current needs;

- Decrease in reserves and increase operating costs, due to the difficulty of extracting deep oil deposits;

- Efficiency of oil and shale gas exploitation, under the conditions in which "the United States is now the world's fastest growing oil producer, achieving what would have been unimaginable just a few years ago. Shale plays are prolific but require continual investment due to rapid decline rates from individual wells" (International Security Advisory Board, 2014, p. 3);
- Climate change that makes new areas available for hydrocarbon extraction, such the arctic area, that is attractive for US, Canada, Russia, Norway;

- Etc.

\section{The Importance of Energy Resources of the Middle East}

The Middle East is an extremely rich area of fossil energy resources, which are the basis for the functioning of the economy in most developed countries. Taking into account the abundance of resources available here, we can say that the strategic importance of the region will remain particularly high for a very long time, and that the attention of the great powers will focus on controlling or influencing the events taking place here because "the concentration of so much of the world's hydrocarbons in this geographical location means that as long as the modern economy depends on the supply of oil and natural gas, the Middle East will play a key role in global politics and economy" (Luft, 2009, p. 1). The strategic importance of the Middle East is also very high today when major powers or emerging powers seek to gain as much influence as possible and prevent other competitors from doing the same thing, which translates into maintaining conflicting states and supporting different camps in local or internal conflicts occurring in the region.

The analysis of the statistical data highlights the energetic characteristics of the area, its role in ensuring the energy resources needed for the developed countries and also anticipates the importance of the area in the future. Ensuring the energy security of energyconsuming states depends to a large extent on the control of this region and on the energy security of the region itself. Nowadays control of the region is no longer direct, but by influencing the policies of the states in the region, by supporting them in various projects, by investing in 
infrastructure, by encouraging the oil companies from the strong states to invest in the region, by ensuring a certain technological transfer etc.

According to data published in the Statistical Yearbook produced by ENI (Ente Nazionale Idrocarburi - National Hydrocarbons Authority), at the level of year 2016, in the Middle East we can fiind $48 \%$ of the global hidrocarbons reserves, while in the other main regions we have the following situation: $20 \%$ in South America, $13 \%$ in North America, $8 \%$ in Africa, $7 \%$ in Russia, while in Europe there is only $1 \%$ of the world's reserves. Also among the top 10 states with major oil reserves 5 are in the Middle East. The absolute world leader in terms of reserves is Venezuela (18\%), followed by Saudi Arabia (16\%), Canada (10.2\%), Iran (9.5\%), Iraq (8.5\% $6.1 \%)$ and the United Arab Emirates (5.9\%) (ENI, 2016, pp. 2-3). According to the same source, in the coming decades, the Middle East will remain among the few areas where hydrocarbon reserves will continue to last, taking into account the existing quantities and the annual global consumption rate. Europe will deplete its oil reserves over the next 10 years, Russia in 23 years, while the Middle East will exhaust its hydrocarbon reserves at steady consumption in about 74 years. The detailed situation at the level of Middle East states is shown in Figure no. 1.

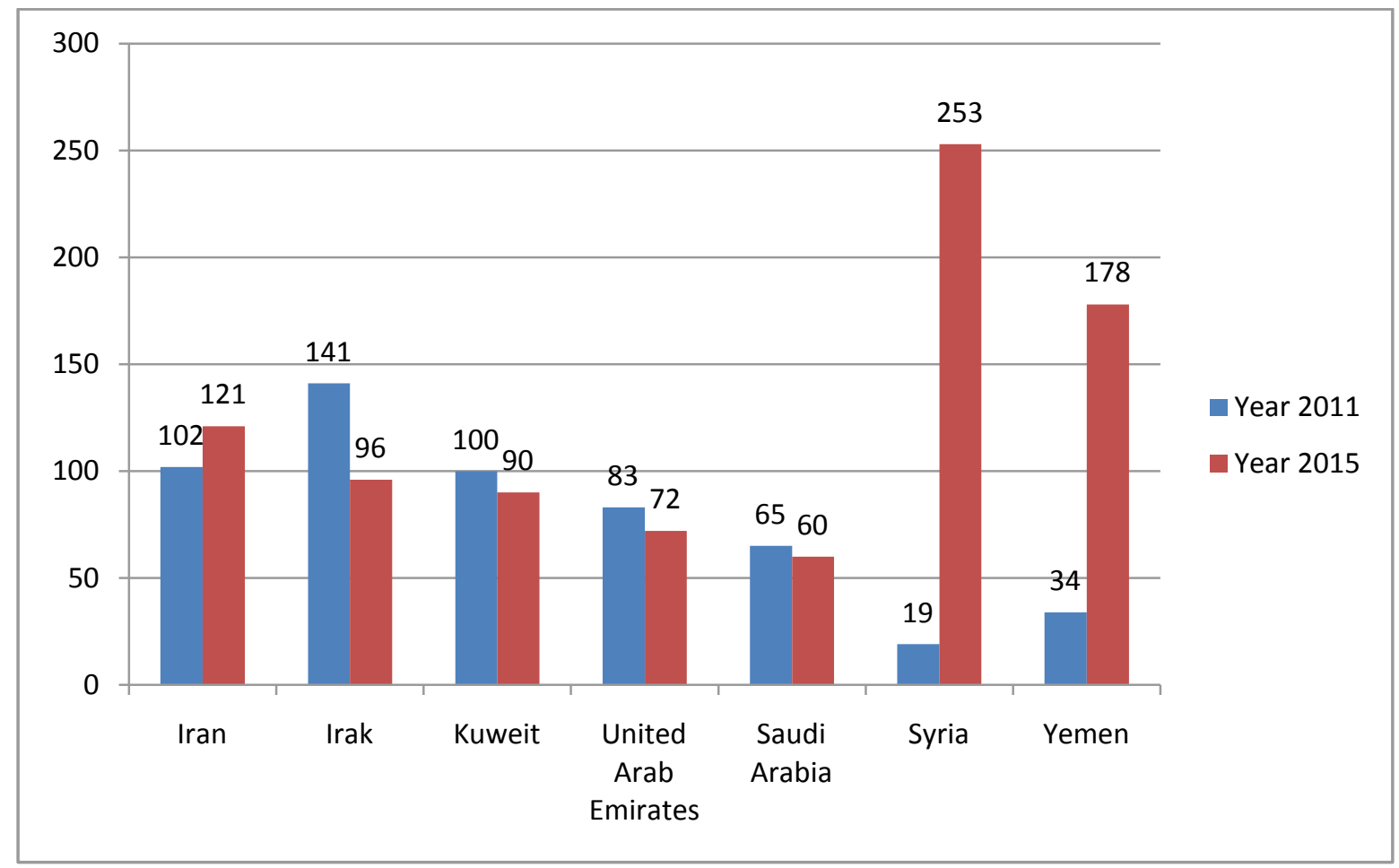

Figure no. 1: Reserves of oil (in years) based on the current production rate (Eni, 2016, p. 16)

In the case of Syria and Yemen we can see an extreme change in the stock situation because of the sharp decline in production due to internal conflicts, and this difference is best seen in the analysis of the data available for 2011 and 2015. We believe that the data provided is all the more significant, as we notice that the Middle East countries have an important market share at the moment and an important production 
capacity. Thus, according to data provided by ENI, in the Statistical Yearbook (ENI, 2016, p. 8), we find out that the world's largest world oil producer is the US, with $14.1 \%$ of total production, followed by Saudi Arabia with $13.2 \%$ and Russia with $12 \%$. In the top 10 of the world's leading oil producers, we also find four other Middle Eastern countries: Iraq (4.4\%), United Arab Emirates (4.1\%), Iran (3.9\%) and Kuwait $(3.4 \%)$.

Middle East countries play a particularly important role in the global energy market and developments in this region can be felt globally. The energy security of Europe and the world at large depends on the energy security of the Middle East, as hydrocarbons still occupy a dominant position in each country's energy basket, and the possibilities for replacing hydrocarbons are limited, although there is concern about this. At present, fossil energy resources (oil, gas and coal) account for $81 \%$ of the global energy mix, and by 2040 the share will remain extremely high, standing at around $77 \%$, and oil and natural gas will account for $53 \%$ (OPEC, 2016, p. 9).

The European Union is directly interested in the evolution of events in the Middle East, even though the Member States do not manifest themselves as important players in the area. The European Union's energy security depends to a large extent on the stability and security of the Middle East, knowing its high degree of energy dependency, although efforts have been made in recent years to reduce it and increase the share of energy from renewable sources in the European energy mix, the renewable energy reaching a total weight of $25.5 \%$ in 2015 .

Given that in 2014 the European Union imported $8.9 \%$ of its oil consumption from Saudi Arabia's (4th place among the oil providers) and $4.6 \%$ from Iraq (6th place among the oil providers) (Eurostat, 2016), and in 2016 it came largely from the same sources - Iraq (7.7 \%) and Saudi Arabia
$(6.9 \%)$, ie positions 4 and 5 on the list of European Union's oil sources (EU imports of energy products - recent developments, 2017), we can state that the Middle East area could directly influence the EU member states' energy security. The development of viable alternatives to fossil energy requires time, major investments and new technological breakthroughs, and the total replacement of oil is far from turning into reality, as "one in every three barrels of exported crude oil still comes from the Middle East. Yet significant shifts in this sector are transforming the geopolitical equation of oil in the region" (Kaspersen, 2015).

The Middle East enjoys a privileged position worldwide due to its large reserves of hydrocarbons, but at the same time it draws the attention of the great powers, who are willing to do everything in their power to defend their interests and achieve their goals. Therefore, the geopolitical situation of the region will remain extremely complicated, and the security of the states in the region, closely linked to national security, will remain extremely difficult to maintain in the medium and long term.

\section{Conclusions}

The Middle Eastern countries, rich in fossil-energy resources are in a seemingly lose - lose situation. On the one hand, this region is marked by strong violence and political instability, recalling the conflict in Syria, Iraq, the tense situation between Israel and the Arab states, the complex situation of Iran, which has improved its relations with the US and the international community, but the problems have not been fully resolved, the tensions that can put the totalitarian regimes of Saudi Arabia and other states in the region on trial, regimes that keep the power in part and with Western support, by weapons deliveries of tens of billions of dollars. This political instability may affect states' ability to exploit energy resources, transport them to 
European and Asian recipients, jeopardize the physical security of extraction areas, and raise questions among beneficiaries about safety and continuity of exploitation. Also from this point of view, another problem could be the lack of investments in modern technologies that can keep these states competitive in a very active, flexible and innovative market.

Also, states in this area, more than any other state, can face the issue of securing energy infrastructures in the face of increasingly numerous, complex and difficult to anticipate and combat threats. Middle East countries are vulnerable to countless threats that address the rule of law and the state as a whole, but which can especially target energy infrastructures that are vulnerable for at least two reasons: they are true neuralgic points of the energy system because their operation depends on the functioning of many other infrastructures and systems, and because they are very wide and geographically expanded, making them extremely vulnerable to classical or hybrid attacks (Pricopi, 2016, p. 58).

Technological progress, on the other hand, can be a major challenge for the Middle East countries as it allows for wider exploitation at increasingly affordable and environmentally proven low impact of gas and shale oil, which allows the United States and other countries to reduce their dependence on Middle East hydrocarbons or even to ensure their energy independence and at the same time to allow them to enter in the category of exporters of energy resources, offered at a low price, which would be a blow to major energy producing states.

Decreasing energy prices and keeping them low for a longer period of time can deeply affect most of the states whose economy is almost exclusively dependent on the exploitation of energy resources, as manifested both in Saudi Arabia and especially in Venezuela, a state with significant energy resources and a significant market share, but which are on the verge of collapse due to the fall in oil prices and due to extremely harmful and unsustainable internal policies. "The oil-price collapse that started in June 2014 was not just a correction typical of commodity markets. It will be seen retrospectively as the inauguration of a new era" (Noël, 2016, p. 71).

A counter-example in this respect, and which could serve as a model for many countries, is Norway, the European state with the most important energy resources, and which has created an investment fund fueled by hydrocarbon revenue, and which aims to ensure the financial resources necessary for the good functioning of the state after the exhaustion of the fossil resources.

Another possible short-term solution for Middle East countries is China's interest in energy resources in this region and the investments that China might be willing to materialize in order to secure its resources to keep moving this energetic colossus in becoming.

There are solutions for Middle Eastern countries, but there are also many challenges, some of which are outlined above. Another challenge is the increasing concern to reduce the environmental impact and to promote renewable energy in all sectors of the economy and industry. Promoting green energy, correlated with instability in the region, maintaining low oil prices, making shale oil more efficient, exploiting the Arctic deposits by the USA, Canada, Norway, Russia, etc., and doubled by the lack of investment and a strategy in the long run, may intensify tensions in the Middle East. Simply holding hydrocarbon resources, which are available in limited quantities and whose exploitation is becoming more and more expensive, is not a guarantee of the welfare and stability of this region. Long-term strategies, investments and effective policies to reduce the conflict potential of the region are needed. 
In addition to the political, economic or technological measures that the countries of the Middle East can take individually or in cooperation with energy resource recipients such as the European states or China, particular attention should be paid to developing a culture of resilience, both at the level of state institutions and at the organizational level, and not only because resilience is not only about accepting events and bearing their consequences, but rather identifying solutions to important issues and manifesting a proactive, forward-looking attitude. The current society is particularly dynamic, the energy field is changing rapidly, and the issue of energy security should not only be put to energy-consuming states, but also to energy-owning states.

Also, it should not be neglected that the states of the Middle East are extremely divided, with sometimes contradictory interests. Major players in the area, Iran, Saudi Arabia and Israel are in a tense relationship. The history of relations between Israel on the one hand and the Arab states on the other hand is known. We are seeing an increase in potential tensions between Iran and Saudi Arabia, which disputes their supremacy in the region and lead to conflict through intermediaries. Recently, we have seen an intensification of Iran-Syria-Russia cooperation at all levels, including military, as well as a reaffirmation of the solid relationship between the US and Saudi Arabia, which has recently concluded numerous for the supply of arms and military technology worth several hundred billion dollars (David, 2017), over a period of about 10 years. Against this backdrop, Iran is again seen isolated, although its influence and involvement in the region states, such as Syria, Iraq, Yemen, is rising and the only potential ally of international significance could be Russia, which does not miss any opportunity to strengthen its position in the region to the detriment of the US and other Western states.

\section{REFERENCES}

Cîrdei, I.A. (2015). Rolul securității energetice în asigurarea securității naționale şi colective, Sibiu: Techno Media, 80.

David, J.E. (2017). US-Saudi Arabia seal weapons deal worth nearly $\$ 110$ billion immediately, $\$ 350$ billion over 10 years, available at: http://www.cnbc.com/2017/05/20/ussaudi-arabia-seal-weapons-deal-worth-nearly-110-billion-as-trump-begins-visit.html.

ENI. (2016). Reserves/production Ratio - Midlle East, World oil and gas review, 14, available at: https://www.eni.com/docs/en IT/enicom/company/fuel-cafe/WOGR2016.pdf.

Eurostat. (2016). Europe in figures, Eurostat yearbook, available at: http://ec.europa.eu/eurostat/statistics-explained/index.php/Energy production and imports.

Eurostat. (2017). EU imports of energy products - recent developments, available at: http://ec.europa.eu/eurostat/statistics-explained/index.php/EU imports of energy products recent developments\#Main suppliers of natural gas and petroleum oils to the EU.

Fattouh, B. (2007). How secure are Middle East oil supplies? Oxford Institute for Energy Studies, WPM 33, 9.

International Security Advisory Board. (2014). Report on energy geopolitics: Challenges and Opportunities, July 2, 3. 
Kaspersen, A. (2015). The changing geopolitics of oil in the Middle East, available at: https://www.weforum.org/agenda/2015/06/the-changing-geopolitics-of-oil-in-the-middle-east/.

Luft, G. (2009). Dependence on Middle East energy and its impact on global security. In: Stec S., Baraj B. (eds) Energy and environmental challenges to security. NATO science for peace and security series $C$ : Environmental security. Dordrecht: Springer, 1.

Noël, P. (2016). The new oil regime, Survival: Global politics and strategy, Volume: 58, 71, available at: https://www.iiss.org/en/research/economic-s-and-s-energy-ssecurity/58-5-08-noel-1b53.

Organization of the Petroleum Exporting Countries - OPEC (2016). World oil outlook, 9, available at: http://www.opec.org.

Pricopi, M. (2016). Studiu privind efectele războiului hibrid asupra infrastructurilor critice, în Bârsan, G., Dinicu, A. \& Badea, D. (Coord), Analiza şi modelarea conceptuală a situaţiilor complexe - studii interdisciplinare, Sibiu: Editura Academiei Forţelor Terestre „Nicolae Bălcescu”, 58. 